\title{
Socio-economic inequalities in the use of dental care in urban and rural areas in Poland
}

\author{
Dorota Elżbieta Piotrowska ${ }^{1, A-F}$, Bartosz Pędziński ${ }^{1,2, A-B, D-F}$, Dorota Jankowska ${ }^{3, B-C}$, \\ Dorota Huzarska, ${ }^{4, B}$, Angelika Edyta Charkiewicz ${ }^{1, F}$, Andrzej Stanisław Szpak ${ }^{5, F}$ \\ ${ }^{1}$ Department of Public Health, Medical University, Białystok, Poland \\ ${ }^{2}$ Medical Centre, Łomza, Poland \\ ${ }^{3}$ Department of Statistics and Medical Informatics, Medical University, Białystok, Poland \\ ${ }^{4}$ Department of Medical Law and Medical Deontology, Medical University, Białystok, Poland \\ ${ }^{5}$ Department of Epidemiology and Biostatistics, Institute of Rural Health, Lublin, Poland \\ A - Research concept and design, B - Collection and/or assembly of data, C - Data analysis and interpretation, \\ $D$ - Writing the article, E - Critical revision of the article, F - Final approval of article

\begin{abstract}
Piotrowska DE, Pędziński B, Jankowska D, Huzarska D, Charkiewicz AE, Szpak AS. Socio-economic inequalities in the use of dental care in
\end{abstract} \\ urban and rural areas in Poland. Ann Agric Environ Med. 2018; 25(3): 512-516. doi: 10.26444/aaem/89917
}

\section{Abstract}

Introduction. The issue of inequalities in the use of health services and health inequalities between urban and rural dwellers is a subject of numerous scientific reports, but similar publications on dental health are scarce.

Objective. The aim of this study is to assess the correlations between the use or non-use of dental services and the classical socio-economic factors (SES) in urban and rural groups in a representative population of Poland.

Materials and method. The analysis consisted in desk research based on a questionnaire survey conducted by the Central Statistical Office of Poland on 12,532 individuals (urban areas - 6411, rural areas - 6121) in 2013. The chi-squared test, multivariate and univariate logistic regression models were applied.

Results. There were major differences in the use of dental services depending on income level, education and source of income among rural and urban populations, as well as differences between these populations. Urban dwellers had 1.34 times greater odds of using dental services than rural ones ( $95 \% \mathrm{Cl}: 1.20-1.51)$. In the case of the highest income group, the odds were $3.26(95 \% \mathrm{Cl} 2.21-4.83)$ times greater in cities and $2.07(95 \% \mathrm{Cl} 1.51-2.85)$ times greater in villages than the odds in the lowest income group. In the highest education group, the odds were $1.58(95 \% \mathrm{Cl} 1.17-2.13)$ times greater in urban areas and $2.08(95 \% \mathrm{Cl} 1.48-2.91)$ times greater in rural areas than the odds in the lowest education group.

Conclusions. There are considerable inequalities in the use of dental services, yet the differences in non-use, despite such a need, are less evident. This could imply that health disparities arise not only from economic constraints and unavailability of health care, but also from health attitudes and behaviours.

Key words

dental public health, rural/urban environment, health disparities, health inequalities, socio-economic factors

\section{INTRODUCTION}

Health inequalities resulting from socio-economic factors, such as place of residence, income level, education level and source of income, have been proved in a range of studies in Poland and abroad. Socially disadvantaged people are characterised by a worse health condition and a greater demand for health care than people with a high socioeconomic status (SES) [1-2].

A noteworthy example of health inequalities is life expectancy at birth for men in Poland by place of residence. According to the 2016 data provided by the National Institute of Public Health - Institute of Hygiene, life expectancy at birth for men in towns with a population below $5 \mathrm{~K}$ was 2.3 years shorter than in the largest cities (above 500K), and 0.2 years shorter than in villages.

Inequalities in life expectancy at birth for men in terms of education are also remarkable. Life expectancy at 30 for Polish men with higher education was almost 12 years longer than those with lower-secondary and below. In the case of Polish women at that age, the differences were smaller - 5.1 years [3].

Address for correspondence: Dorota Elżbieta Piotrowska, Department of Public Health, Medical University of Bialystok, UL.Szpitalna 37, 15-295 Białystok, Poland e-mail: dorota.e.piotrowska@gmail.com

Received: 12.02.2018; accepted: 12.04.2018; first published: 17.05.2018
Health inequalities are noticeable also in a subjective assessment of the health condition of Poles depending on their status on the labour market. Only 3.5\% of the employed respondents declared a poor or a very poor health condition, while this percentage was 3 times higher (9.6\%) in the group of the unemployed respondents, and 7 times higher (23.4\%) in the group of economically inactive persons [4].

Inequalities in access to health care, among others, influence the objective and subjective measures of the health condition. The EU-SILC 2015 survey on unmet needs for medical examination among the Polish population reveals considerable differences depending on the income level. In the highest income group, 10\% of the respondents declared that their needs of this kind were not met, whereas in the lowest income group the percentage was 15.9\% [5].

The above health disparities and access to health services have been well examined in the population of Poland [6-10] and many other countries worldwide [11-14]. However, in the area of dental care, the issue has not been sufficiently investigated. The publications describing the observations made in the 1980s and the 1990s [15-16] point to major inequalities in oral health between rural and urban populations, while current reports seem to imply that the inequalities are decreasing $[17,18]$. 


\section{OBJECTIVE}

The aim of this study was to analyse the use and non-use (despite such a need) of dental services in rural and urban populations. The socio-economic characteristics of both populations were analysed by disposable income, education level, and main source of income.

\section{MATERIALS AND METHOD}

Analysis was based on desk research, the 'Health Care in Households' study conducted by the Central Statistical Office of Poland (GUS) in the last quartile of 2013. The survey was performed with the PAPI (Paper and Pen Personal Interview) method. The questions were answered by persons aged over 15. Information about younger individuals were provided by those who were familiar with the children's situation: their parents or guardians. The study covered 4,584 households, which corresponded to 12,532 people. The application of the representative method in this research ensured a scientific ground for extrapolating the results from a random sample of households participating in the survey to all households in Poland $(13,337)$. The average age in the studied group was 40.02 years, median $41.00\left(Q_{1}=21.00 ; Q_{3}=58.00\right)$, range from $0.00-98.00,6,520$ women, 6,012 men. The distribution of the examined population by gender and age are presented in Table 1.

Table 1. Demographic characteristics of the studied population

\begin{tabular}{lcc}
\hline Age & Women & Men \\
\hline $0-19$ & $1,487(20.8 \%)$ & $1,487(24.7 \%)$ \\
\hline $20-39$ & $1,641(25.2 \%)$ & $1,619(26.9 \%)$ \\
\hline $40-59$ & $1,900(29.1 \%)$ & $1,719(28.6 \%)$ \\
\hline $60-79$ & $1,360(20.8 \%)$ & $1,070(17.8 \%)$ \\
\hline $80-98$ & $263(4.0 \%)$ & $117(1.9 \%)$ \\
\hline
\end{tabular}

Income was analysed in PLN by quintile groups: I: $\leq$ 722.50; II: 723.31-1,033.75; III: 1,033.93-1,350.00; IV: $1,350.08-1,850.00 ; \mathrm{V}: \geq 1,850.20$. Education was classified in accordance with the International Standard Classification of Education (ISCED 2011); low education: level 0-2, medium education: level 3-4, high education: level 5-8. The main source of income, classified by GUS into 9 classes, was divided into 6 classes for the purpose of this analysis: cl. 1: annuities and pensions, cl. 2: farm income, cl. 3: other sources, cl. 4: self-employed, cl. 5: social benefits, cl. 6: wages and salaries.

Analysis of the dependencies of using dental treatment or resigning from such services, despite such a need, on individual (single) socio-economic factors was performed with the use of the non-parametric chi-squared test. The relevance of the analysed factors was also confirmed through univariate logistic regression analysis. For the purpose of assessing the simultaneous impact of all discussed aspects, the multivariate logistic regression model was applied. Intensification of the considered risk factors was presented in terms of odds ratio.

\section{RESULTS}

Urban and rural areas. The percentage of people using dental care in cities $(12 \%)$ was significantly higher $(\mathrm{p}<0.0001)$ than in villages (9.18\%). However, the differences were not statistically significant in the case of non-use, despite such a need (urban areas $-4.8 \%$, rural areas $-4.4 \% ; \mathrm{p}=0.30$ ). This was confirmed by the results of the univariate logistic regression analysis. The odds of using dental advice among urban dwellers were 1.34 times higher than for rural dwellers (OR 1.34, 95\% CI: $1.20-1.51)$. Place of residence was a statistically insignificant factor when analysing resignations from dental care, despite such a need (OR 1.09, 95\%, CI: 0.92-1.30).

Income level. There was a significant relation $(\mathrm{p}<0.001)$ between the income level and the use and non-use of services, despite such a need both in cities and villages (Fig. 1, Fig. 2). This was confirmed by the multivariate logistic regression analysis. The odds of using dental care for persons belonging to the highest income group was 3.26 (95\% CI 2.21-4.83) times greater in the urban population, and 2.07 (95\% CI $1.51-2.85)$ times greater in the rural population than in the lowest income group (Tab. 2) with other parameters set. With respect to non-use, the odds ratio for the highest income group relative to the lowest was 0.38 (95\% CI $0.24-0.60)$ in cities and 0.53 (95\% CI $0.33-0.85)$ in villages (Tab. 3).

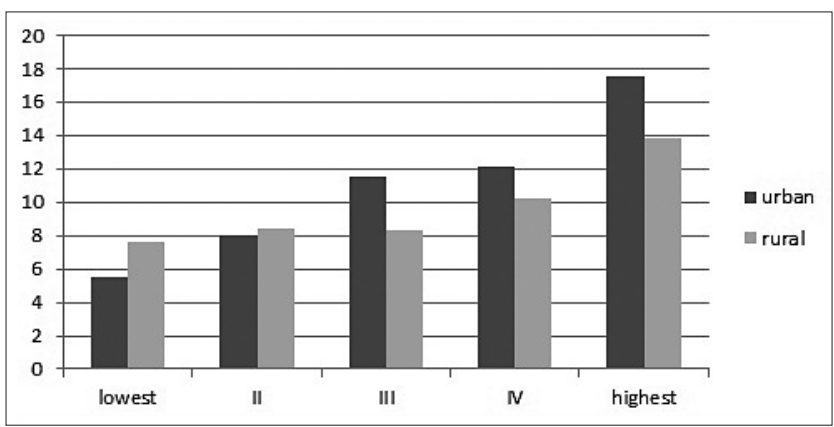

Figure 1. Income and use of dental care: urban $(p<0.001)$ and rural $(p<0.001)$ areas.

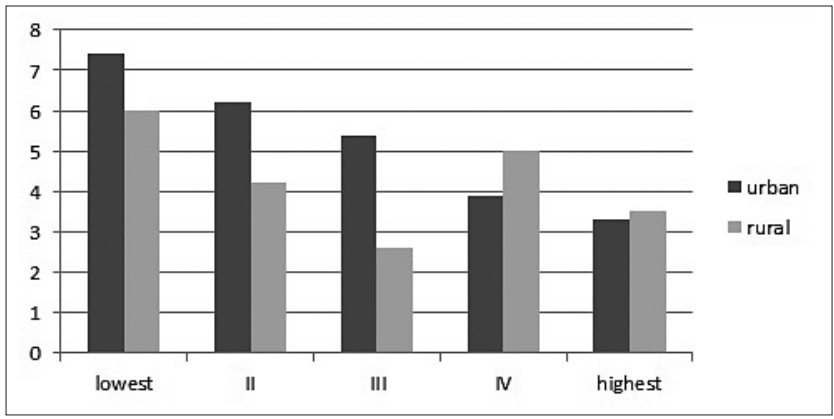

Figure 2. Income and non-use of dental care despite such a need: urban $(p<0.001)$ and rural $(p<0.001)$ areas.

Education levels. As in the case of income, education level had a statistically significant influence on the use of dental services in both urban and rural areas $(p<0.001)$ (Fig 3). Regarding resignations, in turn, statistically significant differences were noticed only in the urban population (Fig. 4). This was confirmed by logistic regression analysis; the odds of using dental care among people with the highest education were 1.58 (95\% CI 1.17-2.13) times greater in the urban population, and 2.08 (95\% CI 1.48-2.91) times 
greater in the rural population than in the group with the lowest education with other parameters set (Tab. 2). Regarding resignations, the logistic regression model showed a significant dependence only in the urban population for those with medium education (OR 1.76 95\% CI 1.17-2.63) (Tab. 3).

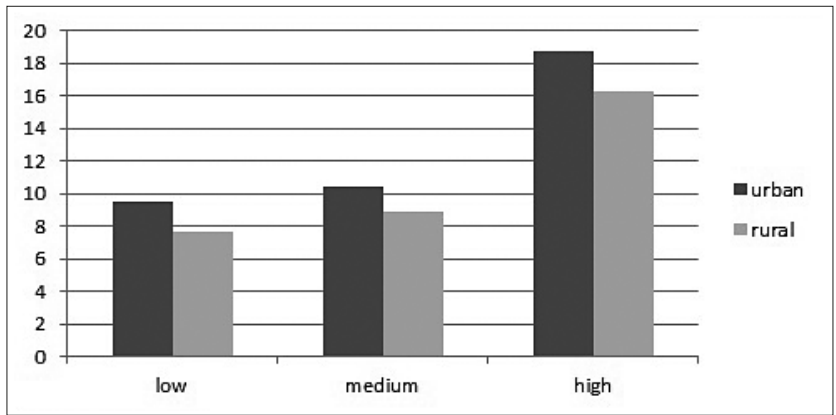

Figure 3. Education level and use of dental care: urban $(p<0.001)$ and rural $(p<0.001)$ areas.

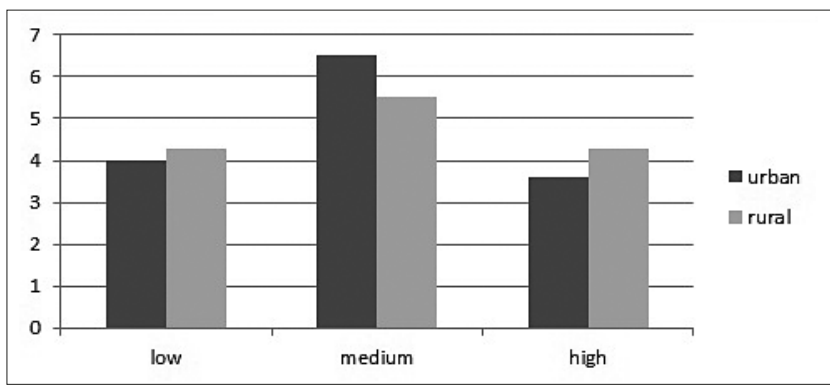

Figure 4. Education level and non-use of dental care, despite such a need: urban $(p<0.001)$ and rural $(p=0.18)$ areas.

Source of income. The use and non-use of dental services was statistically significantly dependent on the source of income in both cities and villages $(p<0.05)$ (Fig. 5, Fig 6). When assuming pensioners and annuitants as the reference group, the odds for use were significantly higher in the group of people receiving social benefits (cities: OR 2.26; 95\% CI 1.47-3.48; villages: 1.91 ; 95\% CI $1.14-3.21$ ) and earning income from other sources (cities: OR 1.7; 95\% CI 1.31-2.22; villages: 2.01 ; $95 \%$ CI $1.51-2.68)$. In the urban population, the odds for use were considerably higher for individuals making a living based on casual and permanent employment contracts (wages and salaries), which was not observed in the rural population (Tab. 2). When analysing resignations

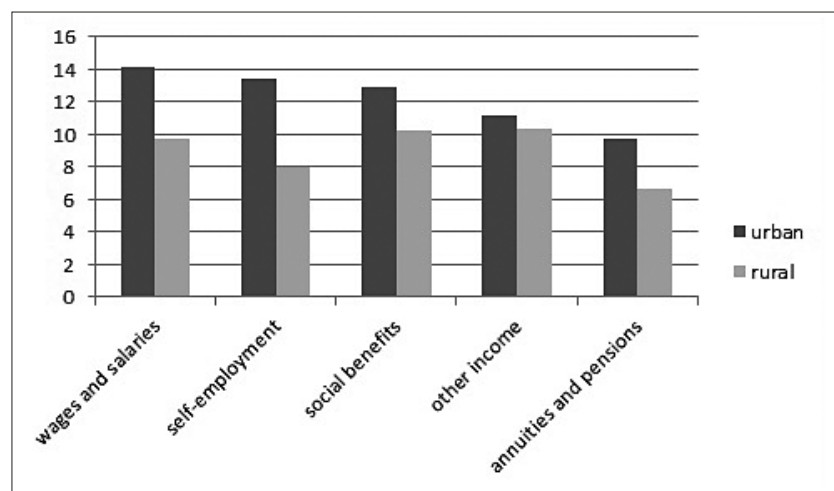

Figure 5. Source of income and use of dental care: urban $(p<0.001)$ and rura $(p=0.006)$ areas

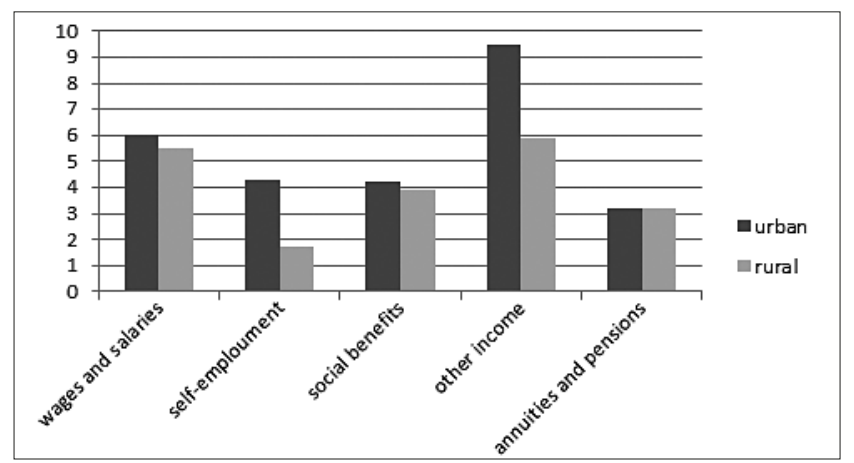

Figure 6. Source of income and non-use of dental care, despite such a need: urban $(\mathrm{p}<0.001)$ and rural $(\mathrm{p}<0.001)$ areas

Table 2. Multivariate logistic regression models for the use of dental care - urban and rural areas

\begin{tabular}{lcccc}
\hline & \multicolumn{2}{c}{ Urban } & \multicolumn{2}{c}{ Rural } \\
\cline { 2 - 6 } & OR & Cl 95\% & OR & Cl 95\% \\
\hline Income - classes & & & & \\
\hline Lowest & ref. & & ref. & \\
\hline II & 1.20 & $0.79-1.84$ & 1.29 & $0.97-1.73$ \\
\hline III & $\mathbf{2 . 0 5}$ & $1.37-3.07$ & 1.27 & $0.94-1.73$ \\
\hline IV & $\mathbf{2 . 3 4}$ & $1.58-3.47$ & $\mathbf{1 . 6 3}$ & $1.19-2.23$ \\
\hline Highest & $\mathbf{3 . 2 6}$ & $2.21-4.83$ & $\mathbf{2 . 0 7}$ & $1.51-2.85$ \\
\hline Education & & & & \\
\hline Low & ref. & & ref. & \\
\hline Medium & 1.03 & $0.79-1.35$ & 1.19 & $0.94-1.52$ \\
\hline High & $\mathbf{1 . 5 8}$ & $1.17-2.13$ & $\mathbf{2 . 0 8}$ & $1.48-2.91$ \\
\hline
\end{tabular}

Source of income

\begin{tabular}{lcccc} 
annuities and pensions & ref. & \multicolumn{3}{c}{ ref. } \\
\hline farm income & 1.27 & $0.29-5.60$ & 1.41 & $0.98-2.03$ \\
\hline other sources & $\mathbf{1 . 7 0}$ & $1.31-2.22$ & $\mathbf{2 . 0 1}$ & $1.51-2.68$ \\
\hline self-employment & 1.23 & $0.83-1.83$ & 0.93 & $0.52-1.66$ \\
\hline social benefits & $\mathbf{2 . 2 6}$ & $1.47-3.48$ & $\mathbf{1 . 9 1}$ & $1.14-3.21$ \\
\hline wages and salaries & $\mathbf{1 . 3 8}$ & $1.12-1.70$ & 1.24 & $0.94-1.64$
\end{tabular}

Values in bold - statistically significant factors in the presented model

Table 3. Multivariate logistic regression models for the non-use of dental care despite such a need - urban and rural areas

\begin{tabular}{lcccc}
\hline & \multicolumn{2}{c}{ Urban } & \multicolumn{2}{c}{ Rural } \\
\cline { 2 - 6 } & OR & Cl 95\% & OR & Cl 95\% \\
\hline Income - classes & & & & \\
\hline Lowest & ref. & & ref. & \\
\hline II & 0.76 & $0.50-1.14$ & $\mathbf{0 . 6 8}$ & $0.48-0.98$ \\
\hline III & 0.67 & $0.44-1.03$ & $\mathbf{0 . 4 0}$ & $0.26-0.62$ \\
\hline IV & $\mathbf{0 . 4 4}$ & $0.28-0.68$ & 0.77 & $0.52-1.14$ \\
\hline Highest & $\mathbf{0 . 3 8}$ & $0.24-0.60$ & $\mathbf{0 . 5 3}$ & $0.33-0.85$ \\
\hline Education & & & & \\
\hline Low & ref. & & ref. & \\
\hline Medium & $\mathbf{1 . 7 6}$ & $1.17-2.63$ & 1.22 & $0.88-1.68$ \\
\hline High & 1.12 & $0.67-1.88$ & 1.08 & $0.62-1.89$ \\
\hline
\end{tabular}

Source of income

annuities and pensions ref. ref.

$\begin{array}{llll}\text { farm income } & 1 & 1.49 & 0.95-2.33\end{array}$

\begin{tabular}{lllll}
\hline other sources & 0.99 & $0.66-1.50$ & 1.05 & $0.70-1.57$
\end{tabular}

self-employment $\quad 1.05 \quad 0.53-2.08 \quad 0.40-0.12-1.31$

$\begin{array}{lllll}\text { social benefits } & \mathbf{2 . 0 4} & 1.23-3.40 & 1.24 & 0.63-2.45\end{array}$

$\begin{array}{lllll}\text { wages and salaries } & \mathbf{1 . 4 2} & 1.04-1.95 & 1.30 & 0.90-1.89\end{array}$

Values in bold designate statistically significant factors in the presented model 
from dental advice, the statistically significant risk factors involved in the source of income was the fact of receiving social benefits (OR 2.04; 95\% CI 1.23-3.40) and earning wages and salaries (OR 1.42; 95\% CI 1.04-1.95), which was not noted in the rural population (Tab. 3.)

\section{DISCUSSION}

The presented study examined the use of dental care depending on SES factors, and showed that socio-economic factors influenced the use of dental services or resignation from such services, despite the need.

Analysis conducted with the use of the non-parametric chi-squared test and the univariate logistic regression model evidenced the existence of statistically significant differences in the use of dental care between rural and urban populations, whereas the differences in resigning from such services, despite the need, were not statistically significant. The obtained results might imply that there are no inequalities between urban and rural populations arising from the impossibility to use the services (e.g. due to lack of money, place of residence), yet inequalities still exist in the use of the services in general. In other words, it can be assumed that rural dwellers are more prone to use the services when such a need arises, but they still generally use the services less often (as, for instance, they resign from preventive services and examinations of the oral cavity). It should be also taken into consideration, that lack of differences in nonuse of dental care while needed may arise from changes in demographical structure. In 2005, the real income of rural inhabitants was lower than that of the urban population by $12 \%$, whereas in 2012 , the difference was only $6 \%$. It is also important to emphasise that residents of rural areas are presently not only farmers, but also commuters to nearby cities [19]. Also deserving attention is the specific structure of dental service funding [20] in Poland and a very limited basket of dental care services guaranteed by NFZ (National Health Fund) [21], e.g. endodontic treatment of only front teeth in adults, the possibility to have removable dentures made once in 5 years, and no option to use light-curing fillings for adults.

The differences in the use between the 2 populations have been noticed during the last 2 decades of the $20^{\text {th }}$ century in Poland, although they seem to have been blurred since the beginning of the $21^{\text {st }}$ century. In 1978, the percentage of adults who used dental services at least once was circa. $40 \%$ in the rural population, and 55\% in the urban, while in 2010 the percentages were comparable, i.e. $57 \%$ and $60 \%$, respectively. Similar observations have been made for the younger age groups. In 1978, only $40 \%$ of 12 -year-olds from rural areas and $70 \%$ of those from urban areas visited a dentist at least once. In 2010, the values of the indicators were similar $75.3 \%$ in villages and $69.6 \%$ in cities [18].

If it is assumed that dental caries is an objective condition requiring dental care, results corresponding to those obtained in the presented study (no differences between rural and urban populations as regards an objective need) were observed in other latest studies on the population of Poland. In 2009, the value of the dental caries treatment ratio among 12-year-olds in the urban population was 0.54 and in the rural one -0.48 , while in the case of adults the ratio was 0.79 for cities and 0.71 for villages [22].
In this study, the disposable income level affected the use of dental care and resignation from it, despite such a need. The odds of using dental services were 3.26 times greater in the urban group and 2.07 in the rural one among individuals with the highest income than among those from the lowest income class. Eurostat data provided similar evidence. 'Too expensive' was the reason for $6.3 \%$ of the respondents from the lowest income group and only $1.6 \%$ of those from the highest income group resigning from a dental visit [23].

International studies have shown a relationship between education level and health condition and health awareness. The percentage of edentulous persons was lower in the group of respondents with high education (4\%) than in the group of people with low education (27\%) [24]. In the case of persons with high education, the necessity to use dentures (36.9\%) was smaller than for those with low education (64.4\%) [25].

The fact of having high education meant that the odds of using dental care were 1.58 times greater in cities and as many as 2.08 times greater in villages than for persons with the lowest education level. This relation had not been examined in the urban-rural relation in Poland to that date. What is important is the substantial improvement in the education level of the rural population. In rural areas, the number of people with a high education has almost quadrupled in the period of 1995 - 2009 [26]. The above changes translate into health awareness and use of dental care [27-28].

The relationship between the way of earning a living and the use of dental care demonstrated in this study cannot be easily compared to reports by other authors, since the categorisation of the sources of income adopted by GUS is not applied in other countries. Scarce reports from the USA imply that in the case of Caucasian mothers, the regularity of dental visits for their children was also determined by their status on the labour market. The odds for a visit to a dentist were smaller for unemployed women (OR 0.68) than for mothers working full-time [29].

Due to the fact that many of the above-mentioned factors influence the use and non-use of dental services, further research in this area is desirable.

\section{CONCLUSIONS}

The performed statistical analyses of the data have shown that:

1) Urban dwellers used dental services more often than rural ones.

2) The frequency of using dental services increased with income, and education grew in both rural and urban groups,

3) The group which used dental care the least often were pensioners and annuitants.

4) The above disparities were not that clear regarding the non-use of such services, despite such a need, which might imply that this is determined not only by the economic status and access to health care, but also by health attitudes and behaviours.

\section{Acknowledgment}

The study was funded by the Medical University of Bialystok, Poland (Project No. N/ST/ZB/15/002/330) 


\section{REFERENCES}

1. Costa SM, Martins CC, Bonfim MdeLC, Zina LG, Paiva S, Pordeus I, Abreu M. A Systematic review of socioeconomic indicators and denta caries in adults. Int J Environ Res Public Health 2012; 9: 3540-3574.

2. Veugelers P J, Yip A M. Socioeconomic disparities in health care use: Does universal coverage reduce inequalities in health? J Epidemiol Community Health 2003; 57: 424-428.

3. Wojtyniak B, Stokwiszewski J, Goryński P, Zdrojewski T. Długość życia i umieralność ludności Polski. In: Wojtyniak B, Goryński P. editors. Sytuacja zdrowotna ludności Polski i jej uwarunkowania. NIZP-PZH, Warszawa; 2016. p. 49-60.

4. Central Statistical Office in Poland; Health status of population in Poland 2014. https://stat.gov.pl/en/topics/health/health/health-statusof-population-in-poland-in-2014,4,1.html

5. Eurostat. Self-reported unmet needs for medical examination by sex, age, main reason declared and degree of urbanization. http://ec.europa. eu/eurostat/web/products-datasets/-/hlth_silc_21

6. WHO. Social ineqalities in health in Poland. WHO Regional Office for Europe; 2012. p. 79-113.

7. Laskowska I. Availability of health services vs. health condition of residents of rural areas in Poland - Analysis performed on the basis of EHIS 2009. Ann Agric Environ Med. 2015; 22(4): 700-703.

8. Panasiuk L, Kosiniak-Kamysz W, Horoch A, Paprzycki P, Karwat D. Tooth loss among adult rural and urban inhabitants of the Lublin Region. Ann Agric Environ Med. 2013; 20(3): 637-641.

9. Mazur J. Inequalities in the health of the school-aged children based on the results of the health behavior in school-aged children HBSC 2014 - In: Wojtyniak B, Mazur J. editors Social inequalities in child and adolescent health in Poland in light of population studies. NIZP-PZH, Warsaw 2016; 2016. p. 129-138.

10. Zieliński A. Nierówności w zdrowiu a polityka społeczna. Przegl Epidemiol. 2015; 69: $817-822$

11. Raittio E, Kiiskinen U, Helminen S, Aromaa A, Suominen AL. Incomerelated inequality and inequity in the use of dental services in Finland after a major subsidization reform. Community Dent Oral Epidemiol. 2015; 43: 240-254.

12. Petersen PE, Kwan S. Equity, social determinants and public health programs - the case of oral health. Community Dent Oral Epidemiol. 2011; 39: 481-487.

13. Devaux M. Income-related inequalities and inequities in health care services utilisation in 18 selected OECD countries. Eur J Health Econ. 2015; 16: 21-33.

14. Marmot M. Health inequalities in the EU - Final report of a consortium. Consortium lead: Sir Michael Marmot; European Comission Directorate-General for Health and Consumer; European Union; 2013. p. 40-56.
15. Bachanek T, Klichowska-Palonka M, Wolańska E, Orłowski M. Comparative study of the permanent dentition among 12-year-old children in the Lublin Region. Zdr Publ. 2009; 119(4): 391-394.

16. Wójcicka A, Zalewska M, Czerech M, Jabłoński R, Grabowska SZ, Maciorkowska E. Dental caries of the developmental age as a civilization disease. Przegl Epidemiol. 2012; 66: 705-711.

17. Kamińska A, Szalewski L, Batkowska J, Wallner J, Wallner E, Szabelska A, Borowicz J. The dependence of dental caries on oral hygiene habits in preschool children from urban and rural areas in Poland. Ann Agric Environ Med. 2016; 23(4): 660-665.

18. Gaszyńska E, Wierzbicka M, Marczak M, Szatko F. Thirty years of evolution of oral health behaviours and dental caries in urban and rural areas in Poland. Ann Agric Environ Med. 2014; 21(3): 557-561.

19. Stolarska A. Changes of income situation of Polish rural families after EU accession. Zeszyty Naukowe Szkoły Głównej Gospodarstwa Wiejskiego Ekonomika i Organizacja Gospodarki Żywnościowej nr 107, 2014: 5-17.

20. Piotrowska D, Pędziński B, Szpak A. Public and non-public financing of dental care services in Poland. Hygeia Public Health 2016; 51(1): 12-17.

21. Regulation of Minister of Health from 6 November 2013 r. regarding guaranteed benefits in the field of dental treatment (Dz.U. 2013 poz. 1462 z późn. zm.)

22. http://www.mz.gov.pl/wp-content/uploads/2014/11/wynik_bada_ mat_2010.pdf

23. http://appsso.eurostat.ec.europa.eu/nui/submitViewTableAction.do

24. Bernabé E, Suominen AL, Nordblad A, Vehkalahti MM, Hausen H, Knuuttila M, Kivimäki M, Watt RG, Sheiham A, Tsakos G. Education level and oral health in Finnish adults: evidence from different life course models. J Clin Periodontol. 2011; 38: 25-32.

25. Tsakos G, Sheiham A, Iliffe S, Kharicha K, Harari D, Swift CG, Gillman G, Stuck AE. The impact of educational level on oral health-related quality of life in older people in London. Eur J Oral Sci. 2009; 117: 286-292.

26. Bartnik E, Biedrzycki K, Bracisiewicz J, Chłoń-Domińczak A,ChoińskaMika J, Czajkowska M, Dąbrowski M, et al. Raport o stanie edukacji 2010.Społeczeństwo w drodze do wiedzy. Instytut Badań Edukacyjnych, Warszawa; 2011. p. 24.

27. Gomes AP, da Silva EG, Gonçalves SH, Huhtala MF, Martinho FC, Gonçalves SE, et al. Relationship between patient's education level and knowledge on oral health preventive measures. Int Dent Med J Adv Res. 2015; 1: 1-7.

28. Paulander J, Axelsson P, Lindhe J. Association between level of education and oral health status in 35-, 50-, 65- and 75-year-olds. J Clin Periodontol. 2003; 30: 697-704.

29. Grembowski D, Spiekerman C, Milgrom P. Disparities in regular source of dental care among mother of Medicaid-enrolled preschool children. J Healt Care Poor Underserved 2007; 18(4): 789-813. 